\title{
The Use Fibrin Sealant after Spinal Intradural Tumor Surgery: Is It Necessary?
}

\author{
Young II Won ${ }^{1}$, Chi Heon Kim ${ }^{1,2,3}$, Chun Kee Chung ${ }^{1,2,3,4}$, Tae-Ahn Jahng ${ }^{2,5}$, Sung Bae Park ${ }^{2,6}$ \\ ${ }^{I}$ Department of Neurosurgery, Seoul National University Hospital, Seoul, \\ ${ }^{2}$ Department of Neurosurgery, Seoul National University College of Medicine, Seoul, \\ ${ }^{3}$ Clinical Research Institute, Seoul National University Hospital, Seoul, \\ ${ }^{4}$ Department of Brain and Cognitive Sciences, Seoul National University College of Natural Sciences, Seoul, \\ ${ }^{5}$ Department of Neurosurgery, Seoul National University Bundang Hospital, Seongnam, \\ ${ }^{6}$ Department of Neurosurgery, Seoul Metropolitan Government-Seoul National University Boramae Medical Center, Seoul, Korea
}

Objective: A fibrin sealant is commonly applied after closure of an incidental or intended durotomy to reduce the complications associated with the leakage of cerebrospinal fluid. Routine usage might not be essential after closure of an intended durotomy, which has clear cut-margins. We investigated the efficacy of fibrin sealants for primary intradural spinal cord tumor surgery. Methods: A retrospective review was performed for 231 consecutive surgically treated patients with primary intradural spinal cord tumors without extradural extension. Fibrin sealants were not used for 47 patients (group I: age, $51.57 \pm 16.75$ years) and were applied to 184 patients (group II: age, $48.8 \pm 14.7$ years). The surgical procedures were identical except for the use of a fibrin sealant after closure of the durotomy. The primary outcome was the occurrence of complications (wound problems, hematoma collection, infection, and neurological deterioration). The covariates were age, sex, body mass index, operation time, pre-/ postoperative ambulation, number of laminectomies, and type of tumor.

Results: Schwannoma was the most common pathology $(n=134)$, followed by meningioma $(n=35)$ and ependymoma $(n=31)$. Complications occurred in 13 patients ( 3 in group I and 10 in group II, $p=0.73)$. The postoperative ambulation status $(p<0.01$; odds ratio, 28.8; 95\% confidence interval, 6.9-120.0) and operation time ( $p=0.04$; cutoff, 229 minutes; sensitivity, 62\%; specificity, $72 \%)$ were significant factors, whereas the use of a fibrin glue was not $(p=0.47)$.

Conclusion: The use of a fibrin sealant might not be essential to reduce complications after surgery for primary spinal intradural tumor.

Key Words: Fibrin tissue adhesive $\cdot$ Spine $\cdot$ Surgical wound infection $\cdot$ Cerebrospinal fluid $\cdot$ Spinal cord neoplasms

\section{INTRODUCTION}

The goal of dural repair includes the containment of neural tissue and restoration of the cerebrospinal fluid (CSF) space around the spinal cord ${ }^{8,19,21)}$. A watertight dural closure allows early ambulation of the patients and reduces complications associated with the leakage of $\operatorname{CSF}^{3,11,24)}$. The rate of CSF leak after intradural procedures is reported to be approximately $11 \%-16 \% \%^{8,19,21)}$. And persistent leakage of CSF leads to postoperative complications such as wound dehiscence, infec-

- Received: November 28, 2015 • Revised: January 3, 2016

- Accepted: January 11, 2016

Corresponding Author: Chi Heon Kim, MD, PhD

Department of Neurosurgery, Seoul National University Hospital, Seoul National University College of Medicine, 101 Daehak-ro, Jongno-gu, Seoul 03080, Korea

Tel: +82-2-2072-3939, Fax: +82-2-744-8459

E-mail: chiheon1@snu.ac.kr

$\otimes$ This is an open access article distributed under the terms of the Creative Commons Attribution Non-Commercial License (http://creativecommons.org/licenses/by-nc/4.0/) which permits unrestricted non-commercial use, distribution, and reproduction in any medium, provided the original work is properly cited. tion and pseudomeningocele formation ${ }^{9,19,21)}$. To supplement the dural closure, a fibrin sealant is frequently used after spinal intradural tumor surgery, and the efficacy of fibrin sealant application has been demonstrated in the literature ${ }^{1,3,5,13,18,24,26}$. Although the supplementation of a fibrin sealant after closure of an incidental or intended durotomy is supported in the literature ${ }^{1-3,18,26}$, routine usage might not be a requirement after an intended durotomy ${ }^{6}$. The dura is incised in the midline with a scalpel for intradural tumors. Consequently, intended durotomies have clear cut-margins, and closure of the dura appears to be easier than in torn-out incidental durotomies. If a watertight dural closure could be achieved by suturing, a supplemental fibrin sealant might not be essential. We investigated whether closure without the use of a fibrin sealant was associated with the occurrence of complications after primary intradural spinal cord tumor surgery.

\section{MATERIALS AND METHODS}

A retrospective review was performed for 231 consecutive surgically treated patients with primary intradural spinal cord 
tumors without extradural extension from February 2008 to December 2013. The study was approved by Institutional Review Board of Seoul National University Hospital Biomedical Research Institute (H-0910-014-296). Fibrin sealants were not used for 47 patients (group I: male:female $=25: 22$; age, $51.57 \pm 16.75$ years) and were used for 184 patients (group II: male:female $=83: 101$; age, $48.8 \pm 14.7$ years) after dural closure. The use of fibrin sealant was at the discretion of the surgeons, and there was no specific indication. We reviewed the medical records including the operation/progression/nursing records and magnetic resonance imaging to identify the patients who experienced complications during postoperative 3 months. The complications included wound problems (leakage of CSF, bulging, and/or dehiscence), hematoma collection, surgical site infection and postoperative neurological deterioration.

\section{Surgical Method and Perioperative Care}

The surgical procedures and postoperative management were similar in both groups, except for the use of a fibrin sealant ${ }^{9}$. A prophylactic antibiotic with first generation cephalosporin was administered once to each patient, beginning 1 hour before the incision, and was continued for 24 hours postoperatively. All the operations were performed with a conventional midline approach and a laminotomy in a prone position. The dura was opened at the midline or slightly off the midline with a scalpel, according to the location of the tumor, without violation of the arachnoid membrane, if possible. After reflection of the incised dura, the arachnoid membrane was separately incised with a fine scalpel and tacked-up to the reflected dura. After tumor removal and meticulous hemostasis, the arachnoid membrane was closed by $8-0$ nylon suture, and the dural closure was performed using 4-0 silk or 6-0 nylon suture with interrupt sutures or continuous locked sutures $^{3)}$. In meningioma cases, the tumor origin of the dura was not resected; it was coagulated ${ }^{9)}$. The artificial dura was used to cover contracted dura, if necessary ${ }^{9}$. The dural sac was filled with normal saline until it was expanded as much as the preoperative state, and the last suture was tied. The fibrin glue (Tisseel, Baxter, IL, USA or Greenplast, Green Cross Corp., Seoul, Korea) was applied to cover the whole closed dura. The lamina was replaced with a mini-plate or a translaminar screw ${ }^{15)}$. The muscle, fascia, and skin were closed in an ordinary layer-by-layer fashion. In particular, the fascia was meticulously and tightly closed with 1-0 Vicryl. Closed-suction drainage was not routinely inserted; however, it was inserted if there was a large amount of bleeding from muscle or epidural space ${ }^{20)}$. All the patients in both groups were encouraged to ambulate from the day of the operation. The closed-suction drainage bag was removed the next day; it was removed earlier, if CSF were suspected to be draining through the drain tube. The surgical wound was closely inspected every day, beginning from the second postoperative day.

\section{Statistical Analysis}

The primary outcome was the occurrence of complications; wound problems (leakage of CSF, bulging, and/or dehiscence), hematoma collection, surgical site infection, and postoperative neurological deterioration. The following factors were considered as covariates; sex, age, the body mass index, number of laminectomy levels, pre-/postoperative ambulation status, laminoplasty or laminectomy, tumor location (intramedullary or extramedullary), operation time, estimated intraoperative blood loss, and insertion of a closed suction drain. The secondary outcomes were the length of the hospital stay, highest body temperature on postoperative days 1 and 2 , and the total amount of closed suction drainage.

Univariate analyses were performed with Student t-test or chi-square test for the continuous or noncontinuous parameters, respectively. The factors with a p-value $<0.2$ were set into the logistic regression analysis. IBM SPSS Statistics ver. 22.0 (IBM Co., Armonk, NY, USA) was used for statistical analysis and a two-tailed $\mathrm{p}$-value of less than 0.05 was regarded as significant.

\section{RESULTS}

The baseline characteristics were not different between the groups (Table 1). The extent of surgery (level of laminectomy) and the frequency of using artificial dura were not different between the groups $(p=0.13$ and $p=0.24$, respectively). Complications occurred in 3 patients (6.4\%) in group I and $10 \mathrm{pa-}$ tients (5.4\%) in group II, and the incidence was not different between the groups $(\mathrm{p}=0.7)$ (Table 2). In detail, a wound problem occurred in 2 patients (4.3\%), and neurological deterioration occurred in 1 patient (2.1\%) in group I and 5 patients (2.7\%) in group II, respectively. A revision operation was necessary because of the collection of CSF in 1 patient in group I and 2 patients in group II. Leakage of CSF through the surgical wound was controlled with a simple suture in 1 patient in group I and 3 patients in group II. Postoperative meningitis occurred in 1 patient of group II and was controlled with antibiotics.

Complications were associated with the operation time, postoperative ambulation status and laminoplasty by the univariate analysis (Table 3). The operation time was $287 \pm 113$ minutes for the patients with a complication and $207 \pm 82 \mathrm{mi}-$ nutes for patients without a complication $(\mathrm{p}=0.03)$. Complications occurred in 9 of 209 patients (4.3\%) with laminoplasty and 4 of 22 patients (18\%) without replacement of the lamina $(p=0.03)$. The postoperative ambulatory patients showed complications in 5 of 212 patients (2.3\%), whereas the postoperative nonambulatory patients showed complications in 8 of 19 patients $(42.1 \%)(\mathrm{p}<0.01)$. The multivariate analysis showed that the postoperative ambulatory status $(\mathrm{p}<0.01)$ and 
Table 1. Characteristics of groups

\begin{tabular}{|c|c|c|c|}
\hline Characteristic & Group I $(n=47)$ & Group II $(n=184)$ & p-value \\
\hline \multicolumn{4}{|l|}{ Sex } \\
\hline Male:female & $25: 22$ & $83: 101$ & 0.32 \\
\hline Age (yr) & $51.6 \pm 16.8$ & $48.8 \pm 14.7$ & 0.26 \\
\hline Height $(\mathrm{cm})$ & $162.1 \pm 8.9$ & $163.1 \pm 9.7$ & 0.51 \\
\hline Weight (kg) & $63.6 \pm 9.5$ & $62.9 \pm 11.9$ & 0.69 \\
\hline Body mass index $\left(\mathrm{kg} / \mathrm{m}^{2}\right)$ & $24.2 \pm 3.2$ & $23.5 \pm 3.0$ & 0.15 \\
\hline Levels of laminectomy & $2.0 \pm 1.0$ & $2.3 \pm 1.1$ & 0.13 \\
\hline Use of artificial dura & 1 & 12 & 0.24 \\
\hline Operation time (min) & $193.7 \pm 82.7$ & $215.5 \pm 86.6$ & 0.12 \\
\hline Preoperative ambulation, yes & 45 & 170 & 0.54 \\
\hline Postoperative ambulation, yes & 45 & 167 & 0.38 \\
\hline Estimated intraoperative blood loss $(\mathrm{mL})$ & $437.1 \pm 459.4$ & $449.0 \pm 408.7$ & 0.87 \\
\hline Laminoplasty & 39 & 170 & 0.09 \\
\hline Closed suction drain & 14 & 38 & 0.18 \\
\hline \multicolumn{4}{|l|}{ Location of tumor } \\
\hline Intramedullary:extramedullary & $5: 42$ & $30: 154$ & 0.33 \\
\hline Schwannoma & 29 & 105 & \\
\hline Meningioma & 5 & 30 & \\
\hline Ependymoma & 4 & 26 & \\
\hline Cavernous malformation & 5 & 7 & \\
\hline Neurofibroma & 1 & 3 & \\
\hline Hemangioblastoma & 1 & 4 & \\
\hline Subependymoma & 0 & 2 & \\
\hline Astrocytoma & 1 & 3 & \\
\hline Oligodendroglioma & 0 & 1 & \\
\hline Others & 1 & 3 & \\
\hline
\end{tabular}

Values are presented as number or mean \pm standard deviation. Group I, without fibrin sealant; group II, with fibrin sealant.

Table 2. Primary outcomes

\begin{tabular}{lcrc}
\hline \hline Variable & $\begin{array}{c}\text { Group I } \\
(\mathrm{n}=47)\end{array}$ & $\begin{array}{c}\text { Group II } \\
(\mathrm{n}=184)\end{array}$ & p-value \\
\hline Complication & $3(6.4)$ & $10(5.4)$ & 0.73 \\
Neurological complication & $1(2.1)$ & $5(2.7)$ & 0.82 \\
Wound problems & $2(4.3)$ & $5(2.7)$ & 0.58 \\
Revision operations & $1(2.1)$ & $2(1.1)$ & 0.57 \\
\hline
\end{tabular}

Values are presented as number (\%).

Group I, without fibrin sealant; group II, with fibrin sealant. "Bulging, cerebrospinal fluid leak, and infection.

operation time $(p=0.04)$ were significant factors, whereas the use of a fibrin glue was not a prognostic factor $(p=0.47)$ (Table 3). The nonambulatory patients showed a 28.8 times higher complication rate (odds ratio [OR], 28.8; 95\% confidence interval [CI], 6.9-120.0). To determine the optimal cutoff value of the operation time, a receiver-operating char- acteristic curve was created (Fig. 1). The area under the curve was 0.72 (95\% CI, 0.56-0.87). The cutoff segmental angle was 229 minutes (sensitivity, 62\%; specificity, 72\%). Lamina replacement appeared to show lower the complication rate $(\mathrm{OR}$, 0.2 ; 95\% CI, 0.04-1.04).

The secondary outcomes (the length of hospital stay, body temperature at postoperative days 1 and 2, and total amount of closed suction drainage) were not different between the groups (Table 4).

\section{DISCUSSION}

This study investigated whether the use of fibrin glue was associated with postoperative complications. The occurrence of complications was not dependent on the use of fibrin glue ( $6.4 \%$ vs. $5.4 \%, p=0.7)$. The use of fibrin glue was not associated with the hospital stay period, body temperature or amount of drainage. The determining factors for the occur- 
rence of complications were the postoperative ambulation ability and operation time.

\section{The Use of a Fibrin Sealant}

Among the patients who underwent spinal intradural surgeries, CSF leakage from the wound is not rare ${ }^{8,10,16,21)}$. A persistent leakage of CSF might cause postoperative complications such as wound dehiscence, surgical site infection and pseudomeningocele formation ${ }^{10,19,21)}$. To reduce such problems, supplementation of a fibrin sealant on the closed dura has been introduced ${ }^{18)}$. Fibrin sealants contain inactivated human fibrinogen and thrombin and mimic the last step of the coagulation cascade ${ }^{6,17}$. In addition to its potent hemostatic properties, a fibrin sealant acts as adhesive agent by a forming fibrin cross-linking polymer ${ }^{6,17}$. Many authors recommend the routine usage of a fibrin sealant to reinforce the durotomy site, and they have reported that the patients treated with the a fibrin sealant had a significantly higher rate of watertight closure than that of the controls ${ }^{3,24)}$ as well as decreased postoperative drainage output and length of hospital stay ${ }^{13,26}$.

The use of a fibrin sealant is not always beneficial. Jankowitz et al. $^{6}{ }^{6}$ retrospectively reviewed 4,835 patients with lumbar surgery and found that the rate of CSF leakage was not re-

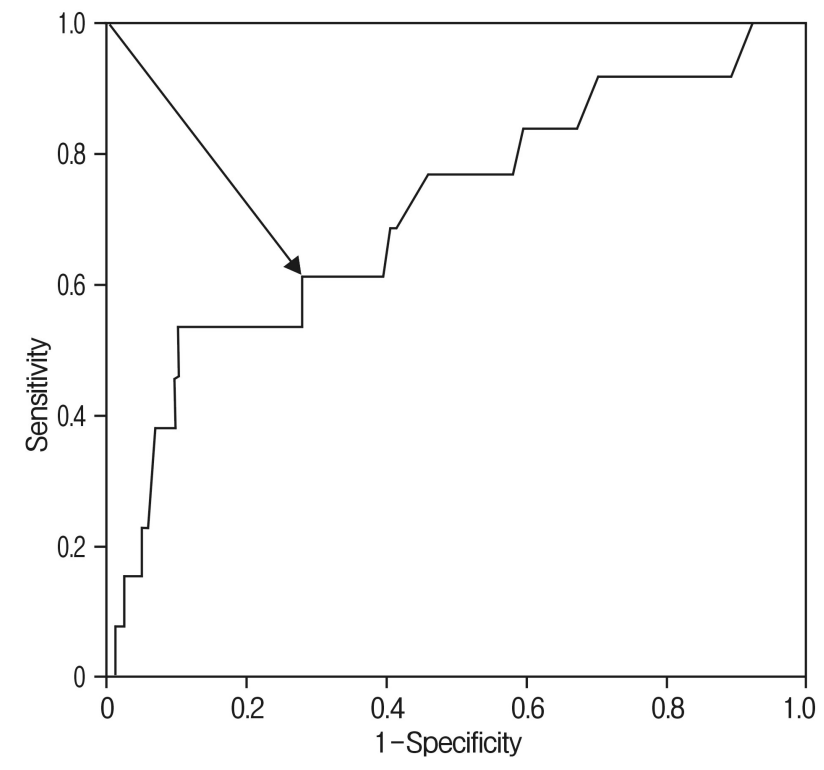

Fig. 1. The receiver operating characteristic curve (ROC). To determine the optimal cutoff value of the operation time, a ROC curve was created. The area under the curve was 0.72 (95\% confidence interval, $0.56-0.87)$. The cutoff was 229 minutes (sensitivity, 62\%; specificity, $72 \%$ ).

Table 3. Risk factors for the occurrence of complications

\begin{tabular}{lccc}
\hline \hline Variable & Univariate & Multivariate & Adjusted OR (95\% CI) \\
\hline The use of fibrin glue & 0.73 & 0.47 & $1.9(0.3-10.0)$ \\
Age & 0.54 & - & - \\
Sex & 0.78 & - & - \\
Body mass index & 0.90 & - & - \\
Operation time & 0.03 & 0.04 & $1.01(1.0-1.1)$ \\
Preoperative ambulation & 1.00 & - & - \\
Postoperative ambulation (reference, yes) & $<0.01$ & $<0.01$ & $28.8(6.9-120.0)$ \\
Number of laminectomy & 0.11 & - & - \\
Type of tumor (IDEM/IM) & 1.00 & - & - \\
Laminoplasty & 0.03 & - & $0.2(0.04-1.04)$ \\
Drain & 0.50 & - & -
\end{tabular}

OR, odds ratio; CI, confidence interval; IDEM/IM, intradural extramedullary/intramedullary.

Table 4. Secondary outcomes

\begin{tabular}{llcc}
\hline \hline Variable & Group I $(\mathrm{n}=47)$ & Group II $(\mathrm{n}=184)$ & $\mathrm{p}$-value \\
\hline Hospital stay (day) & $8.5 \pm 7.6$ & $9.7 \pm 11.1$ & 0.48 \\
Highest body temperature $\left({ }^{\circ} \mathrm{C}\right)$ & & & \\
$\quad$ Postoperative day 1 & $37.7 \pm 0.5$ & $37.8 \pm 0.5$ & 0.44 \\
Postoperative day 2 & $37.5 \pm 0.6$ & $37.5 \pm 0.6$ & 0.66 \\
Amount of drain $(\mathrm{mL})^{*}$ & $323.6 \pm 286.8(\mathrm{n}=14)$ & $303.9 \pm 196.7(\mathrm{n}=38)$ & 0.82 \\
\hline
\end{tabular}

Group I, without fibrin sealant; group II, with fibrin sealant.

*Closed suction drain was inserted for 14 patients in group I and 38 patients in group II. 
duced by the use of a fibrin sealant. In addition, fibrin sealant was not differentiable from a pseudomeningocele in postoperative magnetic resonance imaging, potentially causing a lengthening of the hospital stay, an invasive CSF diversion procedure or a reoperation ${ }^{12,14,23)}$. Fibrin sealant usage might not be a routine recommendation because of those issues and the $\operatorname{cost}^{3,6)}$.

Previous studies did not classify the use of a fibrin sealant according to the completeness of the dural closure ${ }^{3,4,6,7,13,24,25)}$. Frequently, the incidental durotomy margin is uneven, and a watertight dural closure could not be completed with only suture. In such cases, a dural sealant was helpful ${ }^{10,13,22,26}$. The opened dura had clear margins after an intended durotomy, and a watertight dural closure with only suture was possible in most cases ${ }^{3,6}$. The use of a fibrin glue might not be a necessary procedure for patients with primary spinal intradural tumor surgery.

\section{Limitations of This Study}

There was a critical limitation in this study. The study design was a retrospective analysis, and the use of a fibrin sealant was not randomized. Although the baseline characteristics in the study groups were similar, a selection bias was inevitable. Three surgeons performed the surgeries, and the indications for applying a fibrin sealant might not be identical. This study showed that the use of a fibrin sealant might not be essential once a watertight dural closure and tight layer-by-layer wound closure are achieved. Dural closure without the use of a fibrin sealant might be faultless after spinal surgery for intradural tumor. We hope this information will be helpful for surgeons.

\section{CONCLUSION}

The occurrence of postoperative complications was not associated with the use of a fibrin sealant after surgery for a primary intradural spinal cord tumor. The usage of a fibrin sealant after a watertight dural closure might be at the discretion of surgeons.

\section{CONFLICT OF INTEREST}

No potential conflict of interest relevant to this article was reported.

\section{ACKNOWLEDGMENTS}

This work was supported by the Seoul National University Hospital Research Fund (grant number: 0420153090 [20150987]).

\section{REFERENCES}

1. Cain JE Jr, Dryer RF, Barton BR: Evaluation of dural closure techniques. Suture methods, fibrin adhesive sealant, and cyanoacrylate polymer. Spine (Phila Pa 1976) 13:720-725, 1988

2. Cammisa FP Jr, Girardi FP, Sangani PK, Parvataneni HK, Cadag S, Sandhu HS: Incidental durotomy in spine surgery. Spine (Phila Pa 1976) 25:2663-2667, 2000

3. Dafford EE, Anderson PA: Comparison of dural repair techniques. Spine J 15:1099-1105, 2015

4. Epstein NE: Dural repair with four spinal sealants: focused review of the manufacturers' inserts and the current literature. Spine J 10:1065-1068, 2010

5. Ido K, Shimizu K, Nakamura T: Management of cerebrospinal fluid leakage complicating anterior procedures through thoracotomy: report of three cases. Neurosurg Rev 25:174-176, 2002

6. Jankowitz BT, Atteberry DS, Gerszten PC, Karausky P, Cheng BC, Faught R, et al: Effect of fibrin glue on the prevention of persistent cerebral spinal fluid leakage after incidental durotomy during lumbar spinal surgery. Eur Spine J 18:1169-1174, 2009

7. Jeon SH, Lee SH, Tsang YS, Jung TG, Moon KH, Choi G, et al: Watertight sealing without lumbar drainage for incidental ventral dural defect in transthoracic spine surgery: a retrospective review of 53 cases. J Spinal Disord Tech [Epub ahead of print], 2015

8. Kane PJ, el-Mahdy W, Singh A, Powell MP, Crockard HA: Spinal intradural tumours: Part II--Intramedullary. Br J Neurosurg 13: 558-563, 1999

9. Kim $\mathrm{CH}$, Chung CK: Surgical outcome of a posterior approach for large ventral intradural extramedullary spinal cord tumors. Spine (Phila Pa 1976) 36:E531-537, 2011

10. Kim KD, Wright NM: Polyethylene glycol hydrogel spinal sealant (DuraSeal Spinal Sealant) as an adjunct to sutured dural repair in the spine: results of a prospective, multicenter, randomized controlled study. Spine (Phila Pa 1976) 36:1906-1912, 2011

11. Lee SE, Chung CK, Jahng TA, Kim CH: Dural tear and resultant cerebrospinal fluid leaks after cervical spinal trauma. Eur Spine J 23:1772-1776, 2014

12. Lee SH, Park CW, Lee SG, Kim WK: Postoperative cervical cord compression induced by hydrogel dural sealant (DuraSeal ${ }^{\circledR}$ ). Korean J Spine 10:44-46, 2013

13. Nakamura H, Matsuyama Y, Yoshihara H, Sakai Y, Katayama Y, Nakashima S, et al: The effect of autologous fibrin tissue adhesive on postoperative cerebrospinal fluid leak in spinal cord surgery: a randomized controlled trial. Spine (Phila Pa 1976) 30:E347-351, 2005

14. Neuman BJ, Radcliff K, Rihn J: Cauda equina syndrome after a TLIF resulting from postoperative expansion of a hydrogel dural sealant. Clin Orthop Relat Res 470:1640-1645, 2012

15. Park SB, Jahng TA, Kim CH, Chung CK: Thoracic and lumbar laminoplasty using a translaminar screw: morphometric study and technique. J Neurosurg Spine 10:603-609, 2009

16. Saint-Cyr M, Nikolis A, Moumdjian R, Frenette G, Ciaburro $\mathrm{H}$, Harris PG, et al: Paraspinous muscle flaps for the treatment and prevention of cerebrospinal fluid fistulas in neurosurgery. 
Spine (Phila Pa 1976) 28:E86-92, 2003

17. Sawamura Y, Asaoka K, Terasaka S, Tada M, Uchida T: Evaluation of application techniques of fibrin sealant to prevent cerebrospinal fluid leakage: a new device for the application of aerosolized fibrin glue. Neurosurgery 44:332-337, 1999

18. Shaffrey CI, Spotnitz WD, Shaffrey ME, Jane JA: Neurosurgical applications of fibrin glue: augmentation of dural closure in 134 patients. Neurosurgery 26:207-210, 1990

19. Sin AH, Caldito G, Smith D, Rashidi M, Willis B, Nanda A: Predictive factors for dural tear and cerebrospinal fluid leakage in patients undergoing lumbar surgery. J Neurosurg Spine 5: 224-227, 2006

20. Sohn S, Chung CK, Kim CH: Is closed-suction drainage necessary after intradural primary spinal cord tumor surgery? Eur Spine J 22:577-583, 2013

21. Sugawara T, Itoh Y, Hirano Y, Higashiyama N, Shimada Y, Kinouchi $\mathrm{H}$, et al: Novel dural closure technique using polyglactin acid sheet prevents cerebrospinal fluid leakage after spinal surgery. Neurosurgery 57(4 Suppl):290-294, 2005

22. Tan LA, Takagi I, Straus D, OToole JE: Management of intended durotomy in minimally invasive intradural spine surgery: clinical article. J Neurosurg Spine 21:279-285, 2014

23. Tarapore PE, Mukherjee P, Mummaneni PV, Ames CP: The appearance of dural sealants under MR imaging. AJNR Am J Neuroradiol 33:1530-1533, 2012

24. Wright NM, Park J, Tew JM, Kim KD, Shaffrey ME, Cheng J, et al: Spinal sealant system provides better intraoperative watertight closure than standard of care during spinal surgery: a prospective, multicenter, randomized controlled study. Spine (Phila Pa 1976) 40:505-513, 2015

25. Wu J, Jin Y, Zhang J, Shao H, Yang D, Chen J: Hemostatic techniques following multilevel posterior lumbar spine surgery: a randomized control trial. J Spinal Disord Tech 27:442-446, 2014

26. Yeom JS, Buchowski JM, Shen HX, Liu G, Bunmaprasert T, Riew KD: Effect of fibrin sealant on drain output and duration of hospitalization after multilevel anterior cervical fusion: a retrospective matched pair analysis. Spine (Phila Pa 1976) 33: E543-547, 2008 